\title{
Improving the efficiency of heating boiler plants by using the variable-frequency drive with different methods of heat supply regulation
}

\author{
Andrey Pyatin $^{1}$, Aleksander Shempelev ${ }^{1}$, and Ekaterina Popova ${ }^{1, *}$ \\ ${ }^{1}$ Vyatka State University, State Educational Institution of Higher Education, The Electrical \\ Engineering Department; 610000 36, Moskovskaya street, Kirov city, Kirov region, Russia
}

\begin{abstract}
The aim of the work is to improve the energy efficiency of heating boiler plants by reducing the spe-cific electric energy consumption for heat supply by using the variable-frequency drive (VFD) with different methods of heat supply regulation. Hydraulic and thermal calculations of the heating net-work are performed on the example of the real district heating system. Heat network temperature charts of district heating are selected and calculated considering preservation of high quality of district heating. The description of the calculation algorithm of the research and the results of the calculation of the basic mode of district heating heat supply according to the standard temperature chart of varia-ble temperature control are given in the article. Places of installation of VFD are determined on the base of the basic mode. The results of calculation of three different methods of heat supply regulation are presented: standard heat network temperature chart of variable temperature control with using the VFD, extended heat network temperature chart of constant temperature/variable flow control, extend-ed heat network temperature chart using the VFD.
\end{abstract}

\section{Introduction}

The main centralized sources of heat in Russia are combined heat and power plants (CHP) and heating water boiler plants. Taking into consideration the installed capacity, the ratio of heating boiler plants was $68 \%$ in average for 2012-2016, and the ratio of CHP plants was $32 \%[1]$. At the same time, there is a reserve of energy saving in almost every boiler house $[2,3]$.

The efficiency of heat energy production in a boiler house and transportation of heat carrier in the heat network is determined by the possibility of controlling the heat carrier parameters at all stages with the least losses, as well as the technology and equipment used [4,5]. In most boiler plants, regulation is carried out by throttling in valves (which is prohibited), or by means of control valves $[6,7]$. Such regulation is costly in terms of power consumption and equipment life due to large loss of hydraulic (mechanical) and, thus, electri-cal

\footnotetext{
${ }^{*}$ Corresponding author: ekaterina_popova_1993@list.ru
} 
power $[8,9]$. Therefore, the demand for the transition to an adjustable electric drive of the boiler house equipment, first of all pumps, is very high and this problem is urgent [10-15].

In this work we examine the efficiency of heating boilers at various methods of regulating heat supply and maintaining the average internal design temperature in heated build-ings [16].

\section{The aim of the study}

The aim of the work was to assess the efficiency increase of the heating boiler plants by reducing the cost of electricity per unit of heat produced. This cost of electricity was reduced using a variable frequency drive (VFD) of pumps and using various methods of controlling the parameters of the coolant taking into account the losses of thermal energy and coolant in the network while flowing to consumers.

The following tasks were set and solved:

1. Calculation of temperature charts of qualitative and qualitative-quantitative control (extended chart) taking into account leakage and cooling of the coolant in the network for a boiler house;

2. Development of a program for thermal calculation of the boiler house scheme and annual indicators taking into account the use of VFD at pumps and the repeatability (duration) of external temperature intervals through $1{ }^{\circ} \mathrm{C}$;

3. Calculation of the basic operation mode of the boiler house with the standard temperature chart of quality control and without VFD;

4. Calculation of efficient heat supply regulation modes from the boiler house:
a. Standard temperature chart of quality control using VFD;
b. Extended temperature chart of control without VFD;
c. Extended temperature chart of control using VFD.

\section{Methods}

The study of the operation modes for heating boiler plant was carried out on the basis of two regulation equations. The first equation determines the temperature $\tau_{h 1 s}$ of the coolant released from a source at a given relative flow rate $\bar{G}_{h 1 s}$. This temperature provides the designed internal temperature $t_{i d}$ for the current external temperature $t_{e}$

$$
\tau_{\mathrm{h} 1 \mathrm{~s}}=\frac{\tau_{\mathrm{h} 1 \mathrm{c}}-t_{\mathrm{e}} \frac{1+0.5 \alpha_{\text {leak } 1} \beta_{\text {leak }}^{\prime}}{\bar{G}_{\mathrm{h} 1 \mathrm{~s}}-0.5 \alpha_{\text {leak } 1} \beta_{\text {leak }}^{\prime}} \cdot \frac{\delta \tau_{\mathrm{relT} 1}^{\prime}}{1-t_{\mathrm{eh}} / \tau_{\mathrm{h} 1 \mathrm{~s}}^{\prime}}}{1-\frac{1+0.5 \alpha_{\text {leak } 1} \beta_{\text {leak }}^{\prime}}{\bar{G}_{\mathrm{h} 1 \mathrm{~s}}-0.5 \alpha_{\text {leak1 } 1} \beta_{\text {leak }}^{\prime}} \cdot \frac{\delta \tau_{\mathrm{relT} 1}^{\prime}}{1-t_{\mathrm{eh}} / \tau_{\mathrm{h} 1 \mathrm{~s}}^{\prime}}},
$$

The second equation denotes the expected temperature of the coolant returning to the heat source $\tau_{h 2 s}$.

$$
\tau_{\mathrm{h} 2 \mathrm{~s}}=\tau_{\mathrm{h} 2 \mathrm{c}}-\left(\tau_{\mathrm{h} 2 \mathrm{c}}-t_{\mathrm{e}}\right) \frac{1-0.5 \beta_{\mathrm{leak}}^{\prime}\left(1-\alpha_{\mathrm{leak} 1}\right)}{\bar{G}_{\mathrm{h} 1 \mathrm{~s}}-0.5 \beta_{\mathrm{leak}}^{\prime}\left(1+\alpha_{\text {leak} 1}\right)} \cdot \frac{\delta \tau_{\mathrm{relT} 2}^{\prime}}{1-\frac{t_{\mathrm{eh}}}{\tau_{\mathrm{h} 2}^{\prime}}} .
$$

These equations use network-weighted average temperatures $\tau_{h 1 c}$ of the coolant entering the heating systems of consumers and temperatures $\tau_{h 2 c}$ of coolant returning from consumers to the network taking into account cooling and water losses in the network, calculated by the formula $\left(\tau_{h 1 c}-\right.$ sign “+”, $\tau_{h 2 c}-$ sign “-”"): 


$$
\tau_{\mathrm{h} 1(2) \mathrm{c}}=t_{\mathrm{id}}+\frac{\Delta t^{\prime}\left(\frac{t_{\mathrm{id}}-t_{\mathrm{e}}}{t_{\mathrm{id}}-t_{\mathrm{eh}}}\right)^{\frac{1}{1+n}}}{\left(k_{\mathrm{cn}}^{\prime}\left(\bar{G}_{\mathrm{h} 1 \mathrm{~s}}-\alpha_{\text {leak } 1} \beta_{\text {leak }}^{\prime}\right)\right)^{\frac{p}{1+n}}} \pm \frac{\theta^{\prime}\left(\frac{t_{\mathrm{id}}-t_{\mathrm{e}}}{t_{\mathrm{id}}-t_{\mathrm{eh}}}\right)}{2 k_{\mathrm{cn}}^{\prime}\left(\bar{G}_{\mathrm{h} 1 \mathrm{~s}}-\alpha_{\text {leak } 1 \beta_{\text {leak }}^{\prime}}\right)}
$$

In formulae (1-3), the relative water flow rate from the source $\bar{G}_{h 1 s}$ is defined as the ratio of the current consumption from the source $G_{h 1 s}$ to the designed network flow rate of consumers $G_{h n}^{\prime}$, expressed in terms of the designed network factor of the source $k_{c n}^{\prime}$ and the designed heating flow rate $G_{h}^{\prime}$ of all consumers or through network factors $k_{c n . i}^{\prime}{ }^{\prime}$ and designed heating flow rates $G_{h . i}^{\prime}$ of each consumer:

$$
\bar{G}_{\mathrm{h} 1 \mathrm{~s}}=\frac{G_{\mathrm{h} 1 \mathrm{~s}}}{G_{\mathrm{hc}}^{\prime}}=\frac{G_{\mathrm{h} 1 \mathrm{~s}}}{k_{\mathrm{cn}}^{\prime} G_{\mathrm{h}}^{\prime}}=\frac{G_{\mathrm{h} 1 \mathrm{~s}}}{\sum_{i} k_{\mathrm{cn} . i}^{\prime} G_{\mathrm{h} . i}^{\prime}},
$$

and the network coefficients of the consumers are the ratio of the designed heating network flow rate $G_{h n . i}^{\prime}$ of the i-th subscriber to its designed flow rate $G_{h . i}^{\prime}$, and determine the required change in the designed water consumption to it to compensate its cooling in the network:

$$
k_{\mathrm{cn} . i}^{\prime}=\frac{G_{\mathrm{hn} . i}^{\prime}}{G_{\mathrm{h} . i}^{\prime}}=\frac{\theta^{\prime}+2 \delta \tau_{\mathrm{LT} 1 . i}^{\prime}}{\theta^{\prime}+2 \delta \tau_{\mathrm{hT} 1}^{\prime}},
$$

where $\theta^{\prime}$ is water cooling in the design mode; $\delta \tau_{L \mathrm{~T} 1 . i}^{\prime}$ is cooling in the design mode of heat losses and at designed losses; $\Delta t^{\prime}=0.5\left(\tau_{h 1}^{\prime}+\tau_{h 2}^{\prime}\right)-t_{i d}$ is designed temperature head at design temperatures of the supplied $\tau_{h 1}^{\prime}$ and returned $\tau_{h 2}^{\prime}$ coolant at the external temperature for heating designing $t_{e h} ; \delta \tau_{\text {relT1 }}^{\prime}$ is the adopted relative design cooling in the network of the heating water; $\delta \tau_{h \mathrm{~T} 1}^{\prime}=\tau_{h 1}^{\prime} \cdot \delta \tau_{\text {relT1 }}^{\prime} /\left(1-\delta \tau_{r e l \mathrm{~T} 1}^{\prime}\right)$ is design cooling in the supply pipeline; $\tau_{h 1 s}^{\prime}=\tau_{h 1}^{\prime}+\delta \tau_{h \mathrm{~T} 1}^{\prime}$ is design temperature of water at the source; $\delta \tau_{r e l \mathrm{~T} 2}^{\prime}=\delta \tau_{h \mathrm{~T} 1}^{\prime} / \tau_{h 2}^{\prime}$ is the adopted relative design cooling of the network return water; $\alpha_{\text {leak } 1}$ is the adopted ratio of leakages from the supply pipeline; $\beta_{\text {leak }}^{\prime}=\beta_{\text {leak.s }}^{\prime} /\left(1-\alpha_{\text {leak } 1} \beta_{\text {leak.s }}^{\prime}\right)$ is relative leakage value for heating consumption, expressed in design relative leakages for consumption from a source $\beta_{\text {leak.s }}^{\prime}=G_{\text {leak }} / G_{h 1 s}^{\prime}$, constant leakage flow rate $G_{l e a k}$ and design flow rate from the source $G_{h 1 s}^{\prime}=G_{\mathrm{oc}}^{\prime}+\alpha_{\text {leak } 1} G_{\text {leak }} ; n$ and $p$ are indices of the power-law relation between heat transfer from heating devices on temperature head and flow rate.

For our study we selected a real heating system in the village Doronichi of the Kirov region (Russia). This heating network provides thermal energy to 28 apartment buildings with 2417 people living by a two-pipe heat network with temperature charts of $95 / 70{ }^{\circ} \mathrm{C}$ and heating load of $3.72 \mathrm{MW}$ with a design external temperature for heating $t_{e h}$. Hydraulic and thermal network calculations were performed with the specified cooling $\delta \tau_{\text {relT1(2) }}^{\prime}=0.02$ $(2 \%)$, leakages $G_{\text {leak }}=2 \mathrm{t} / \mathrm{h}$. The following parameters were determined: cooling of water to all consumers, their network coefficients $k_{c n . i}^{\prime}$ and flow rates $G_{h n . i}^{\prime}$, as well as network factor $k_{c n}^{\prime}$, flow rates from all consumers $G_{h t}^{\prime}$ and from the source $G_{h 1 s}^{\prime}$.

According to equations $(1,2)$, a temperature-flow chart ( $\tau \mathrm{G}$-chart) was constructed for the parameters of the coolant discharged from the boiler house (Fig. 1). In this chart each outdoor temperature has equivalent heating lines connecting the temperature and flow rate of the supplied or returned to the boiler water. In $\tau \mathrm{G}$-chart any control charts for heat supply from a boiler plant can be constructed and defined, ensuring the desired internal air temperature $t_{i d}$ for consumers $[17,18]$.

To study the efficiency of the boiler house, two control charts were taken, shown in fig. 1 : 
- A regularly standard temperature chart (STC) of quality control (constant/variable flow control),

- A new extended temperature chart (ETC) of qualitative and quantitative control, which has an interval of quantitative regulation (water temperature for consumers is maximum) and an interval of qualitative regulation (water flow is the lowest possible, $40 \%$ of the designed).

The extended temperature chart provides greater cooling of the coolant and lower costs, so it is energy efficient, and the reduction in consumption can be achieved both by throttling and VFD using the network pumps of the boiler house [19-21]. These control charts are shown in the control chart of heat supply from the boiler house of the v. Doronichi (Fig. 1).

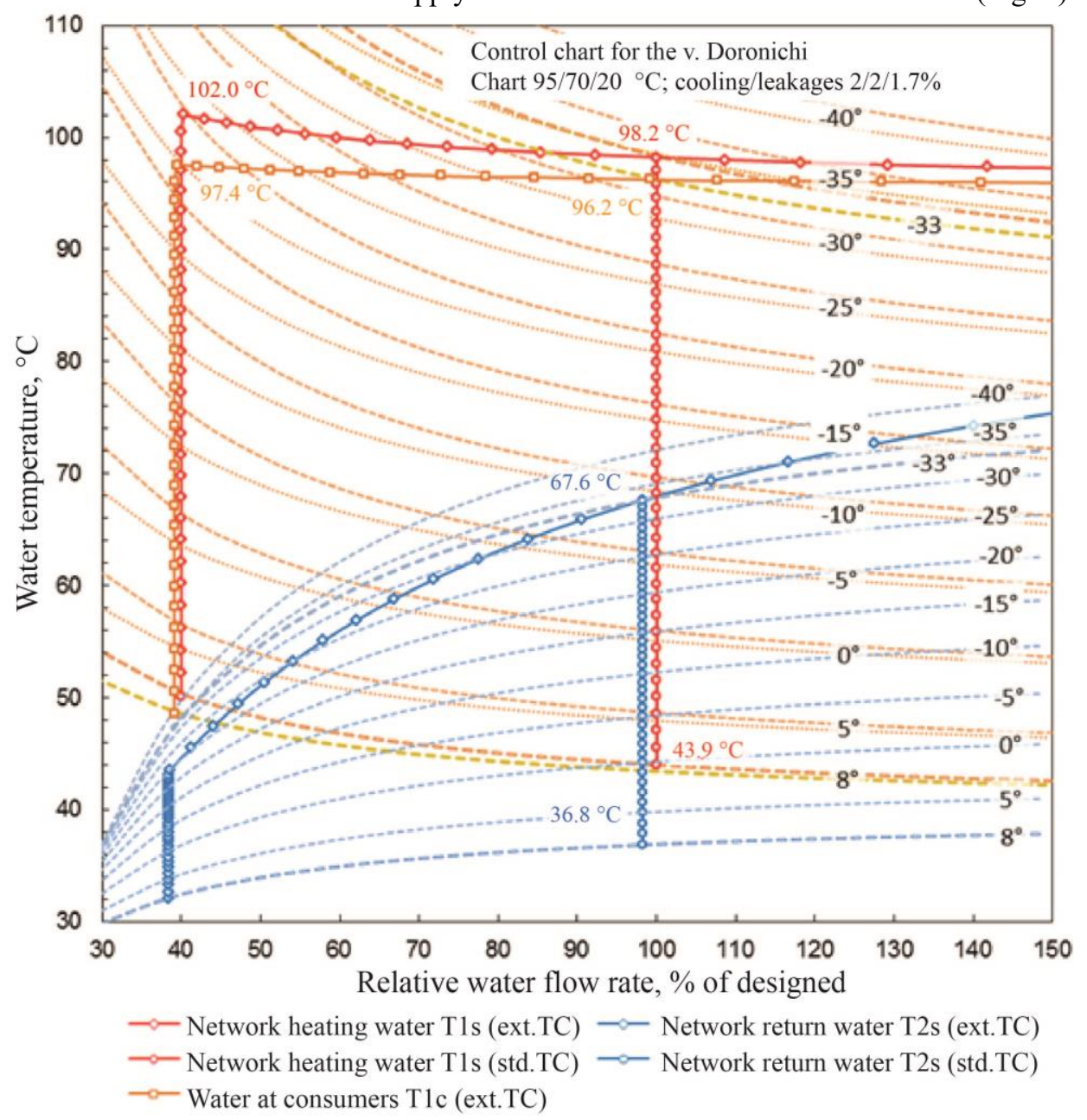

Fig. 1. $\tau G$ - control charts of heat supply from the boiler house.

Temperature charts for water from a source (Ts), average weighted water temperatures for consumers (Tc) according to the standard and extended control charts are shown in Fig. 2 and they are consistent with the control chart (Fig. 1). In addition, in Fig. 2 shows a chart of water temperature $\mathrm{T} 1 \mathrm{~b}$ at the outlet of the boilers. 


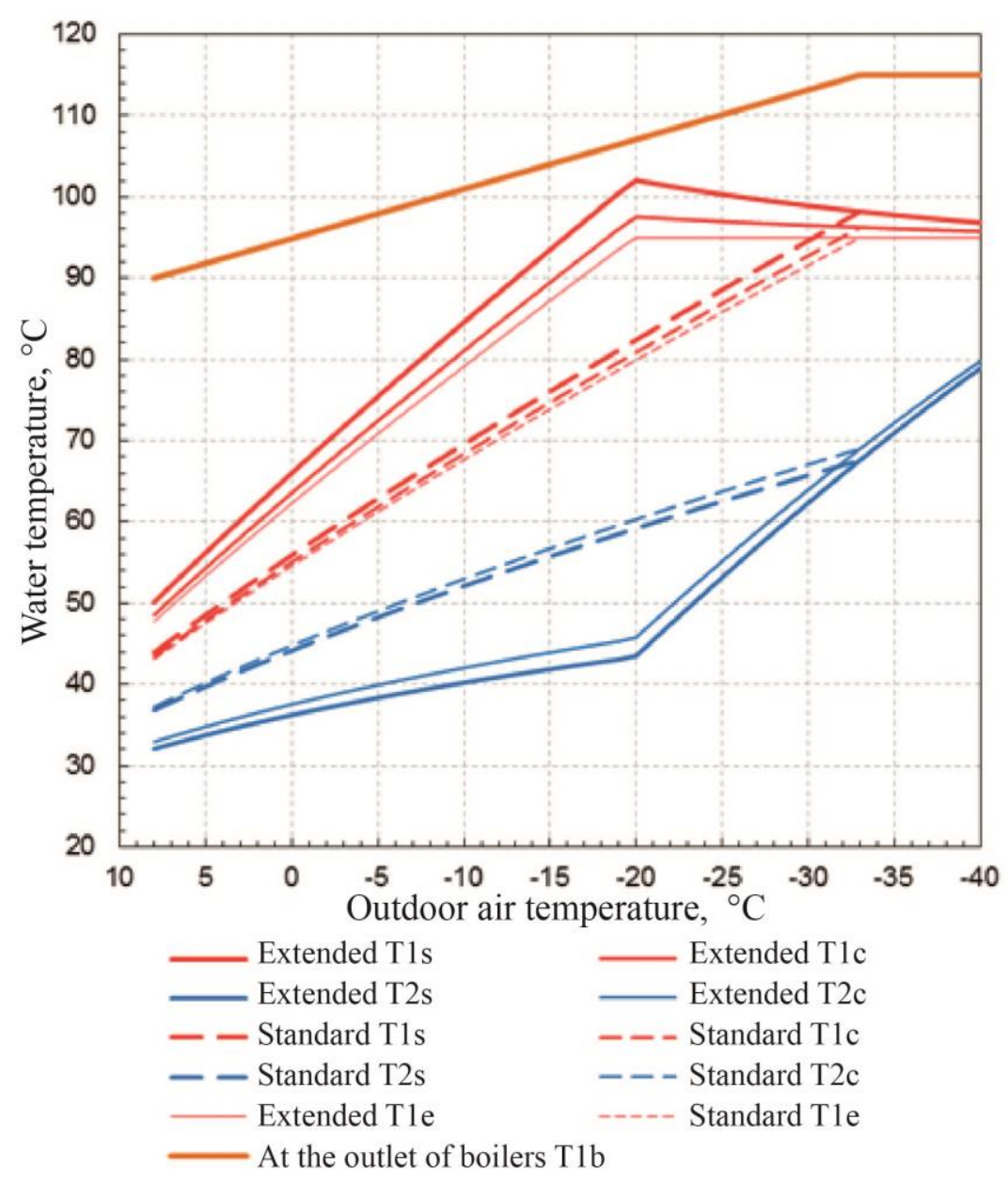

Fig. 2. Temperature charts for coolant at various regulating the heat supply.

For each outdoor temperature we carried out a full thermal and hydraulic calculation of the boiler plant scheme (Fig. 3). In the calculation we took into account the parameters of the coolant discharged according to the selected control chart, as well as throttling in control valves or using VFDs for pumps. For the hydraulic calculation, we used characteristics of pumps, boilers, feeding water heaters, sections of the boiler house and heat network, as well as resistance of consumer heating systems. According to the results of the calculation, the hydraulic power losses were determined at the control valves and other elements of the boiler house circuit. Using data on the duration of the outdoor air temperature intervals (Fig. 4), we determined the annual costs and energy losses in the boiler plant equipment and in the heat network.

At the boiler plant scheme (Fig. 3) for the basic mode and at an outdoor temperature of $20{ }^{\circ} \mathrm{C}$, the following parameters are indicated at each point: flow rate, temperature, pressure, and thermal energy of the flow. Under the scheme we present a plot for pressures in the boiler plant and in the network, which shows pressure losses on control valves. The greatest pressure losses are on the temperature regulator RT, smaller pressure losses are on the network flow regulator $\mathrm{RN}$, which is explained by excessive pressure of the network pumps, 
the smallest pressure losses are obtained in the recirculation temperature regulator $\mathrm{RTr}$, the bypass regulator $\mathrm{RB}$ and the pressure regulator in the network RP.

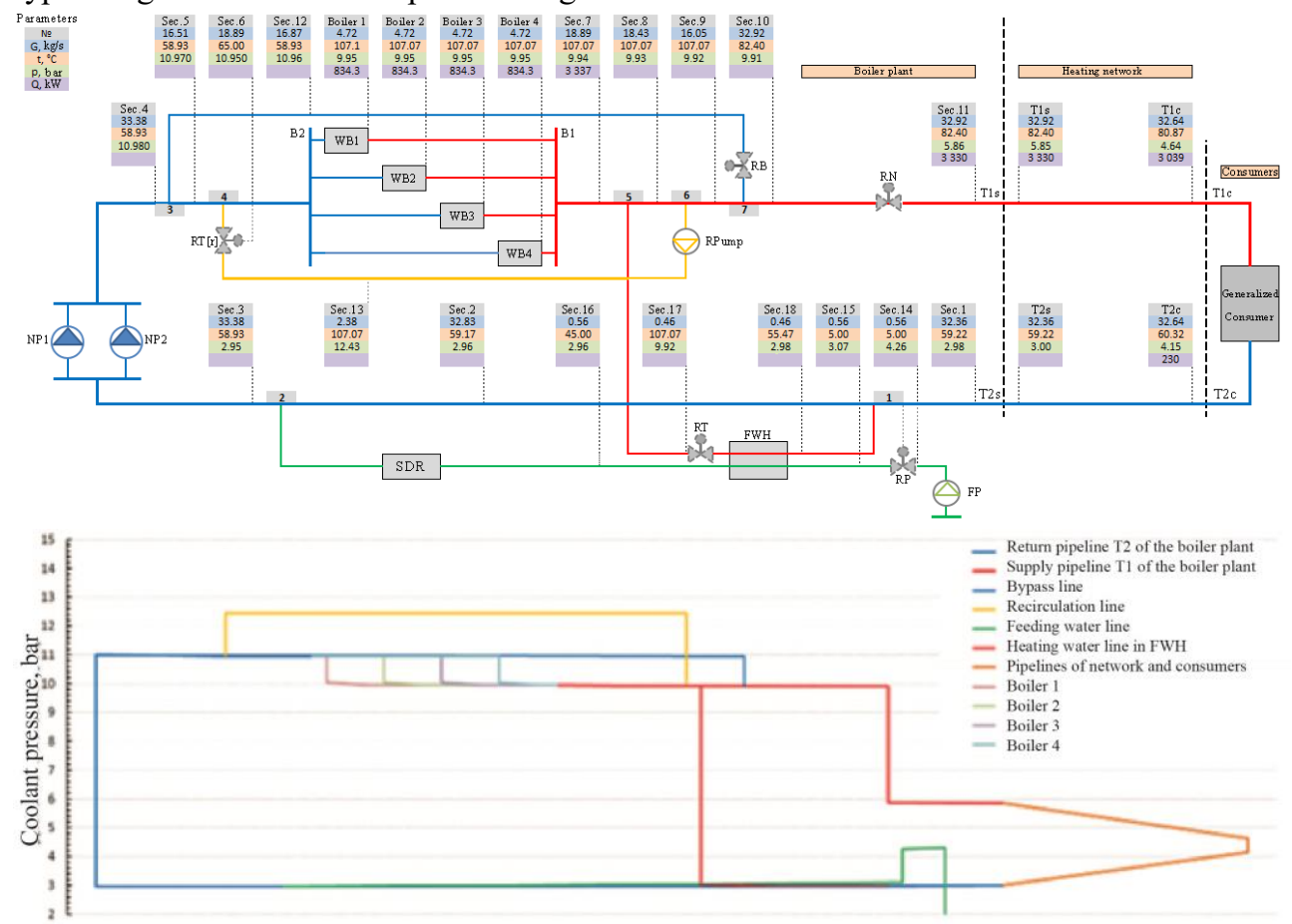

Fig. 3. The design scheme of the boiler plant and pressure plots for the basic mode: WB1, WB2, WB3, WB4 are water heating boilers; NP1, NP2 are network pumps; RPump is recirculation pump; FP is feeding pump; RB is bypass regulator; RN is network flow regulator; RP is pressure regulator; RT is temperature regulator; $\mathrm{RTr}$ is recirculation temperature regulator; FWH is feeding water heater; SDR is reagent dosing station; $\mathrm{C} 1, \mathrm{C} 2$ are boilers collectors; Con is the network consumers, T1s, T2s are lines for forward and return network water of the boiler plant; T1c, T2c are lines for forward and return consumer water.

Fig. 5 shows a water pressure chart in the boiler plant and in the network at efficient regulation of heat supply according to the extended chart using VFD at an outdoor temperature of $-20^{\circ} \mathrm{C}$.

\section{Results and discussion}

The table of calculation data shows the annual performance characteristics of the boiler and heat network in all considered modes of regulation of heat supply and use of VFD. From the comparison with the basic mode (STC) we can draw the following conclusions:

The use of VFD at a standard temperature control chart (STC+VFD) eliminates pressure and energy losses on the RN network flow regulator, on the RTr recirculation regulator, on the RP pressure regulator and reduces energy losses on the RT temperature regulator by almost 3 times, which is explained by pressure reduction in the supply pipe of the boiler plant $[22,23]$. Heat output from the boiler house is not changing, and the consumption of electrical energy is halved. 


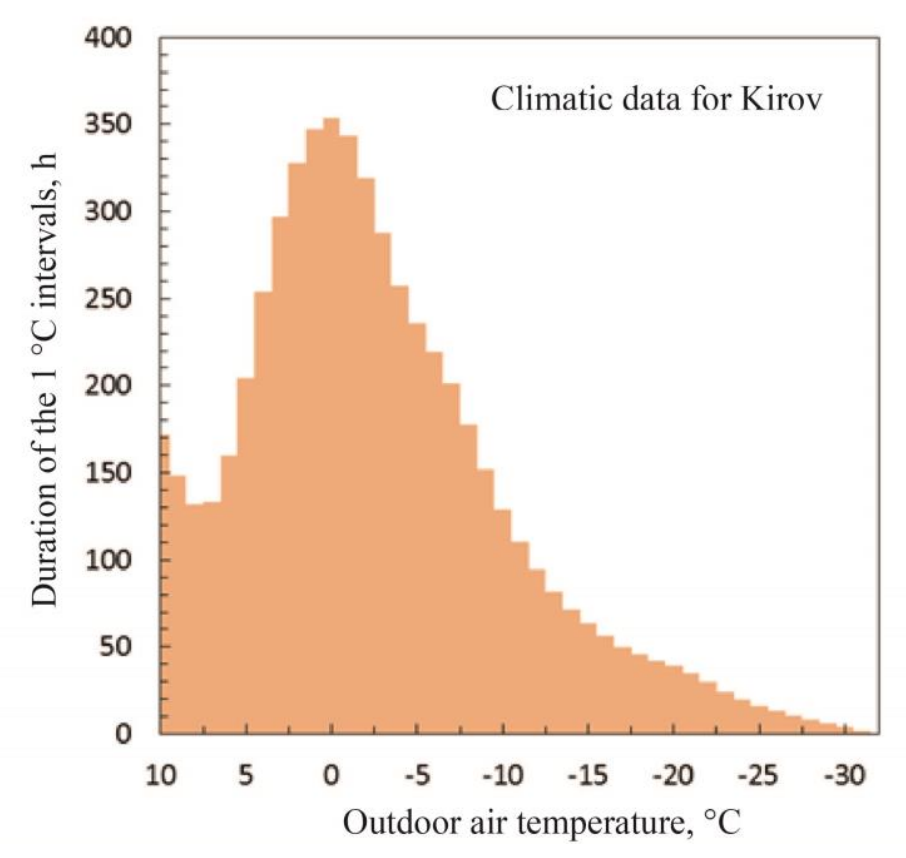

Fig. 4. Duration of the $1{ }^{\circ} \mathrm{C}$ intervals of the outdoor air. 
Table 1. Calculation data of the boiler plant operation modes

\begin{tabular}{|c|c|c|c|c|c|}
\hline $\begin{array}{c}\text { Annual characteristics of the boiler } \\
\text { plant }\end{array}$ & Meas. un. & STC & $\begin{array}{l}\text { STC+ } \\
\text { VFD }\end{array}$ & ETC & $\begin{array}{l}\text { ETC+ } \\
\text { VFD }\end{array}$ \\
\hline \multicolumn{6}{|l|}{ Thermal energy } \\
\hline Thermal energy of fuel combustion & Gkal & 10469 & 10469 & 10509 & 10509 \\
\hline Energy losses in boiler plant & Gkal & 1193 & 1193 & 1193 & 1193 \\
\hline Energy supply from boiler plant & Gkal & 9276 & 9276 & 9316 & 9316 \\
\hline Energy supply for buildings heating & Gkal & 7680 & 7680 & 7680 & 7680 \\
\hline \multicolumn{6}{|l|}{ Electrical and hydraulic energy } \\
\hline Electricity consumption & $\mathrm{kW} \cdot \mathrm{h}$ & 265294 & 127431 & 146043 & 26145 \\
\hline Network pumps NP & $\mathrm{kW} \cdot \mathrm{h}$ & 251019 & 122079 & 130116 & 19573 \\
\hline Recirculation pumps RP & $\mathrm{kW} \cdot \mathrm{h}$ & 12889 & 4744 & 14541 & 5946 \\
\hline Feeding pumps FP & $\mathrm{kW} \cdot \mathrm{h}$ & 1386 & 608 & 1386 & 626 \\
\hline Consumed and lost energy & $\mathrm{kW} \cdot \mathrm{h}$ & 265294 & 127431 & 146043 & 26145 \\
\hline Electrical energy losses in pumps & $\mathrm{kW} \cdot \mathrm{h}$ & 111560 & 53406 & 68764 & 11466 \\
\hline Losses in boiler pipelines & $\mathrm{kW} \cdot \mathrm{h}$ & 2748 & 2748 & 691 & 691 \\
\hline Losses in regulators & $\mathrm{kW} \cdot \mathrm{h}$ & 93534 & 13825 & 65879 & 3279 \\
\hline Losses in regulator RN & $\mathrm{kW} \cdot \mathrm{h}$ & 73771 & & 54392 & \\
\hline Losses in regulator $\mathrm{RB}$ & $\mathrm{kW} \cdot \mathrm{h}$ & 12692 & 12692 & 3160 & 3160 \\
\hline Losses in regulator Rtr & $\mathrm{kW} \cdot \mathrm{h}$ & 3845 & & 4703 & \\
\hline Losses in regulator RT & $\mathrm{kW} \cdot \mathrm{h}$ & 2882 & 1133 & 3289 & 119 \\
\hline Losses in regulator RP & $\mathrm{kW} \cdot \mathrm{h}$ & 344 & & 335 & \\
\hline Losses in boilers and its regulators & $\mathrm{kW} \cdot \mathrm{h}$ & 7319 & 7319 & 7352 & 7352 \\
\hline Losses in network pipelines & $\mathrm{kW} \cdot \mathrm{h}$ & 29691 & 29691 & 2037 & 2037 \\
\hline Losses in building heating systems & $\mathrm{kW} \cdot \mathrm{h}$ & 20442 & 20442 & 1320 & 1320 \\
\hline \multirow{2}{*}{ Electrical energy savings } & $\mathrm{kW} \cdot \mathrm{h}$ & & 137863 & 119251 & 239149 \\
\hline & $\%$ & & $52 \%$ & $45 \%$ & $90 \%$ \\
\hline \multicolumn{6}{|l|}{ Fuel } \\
\hline Annual fuel consumption & toe & 1495.5 & 1495.5 & 1501.3 & 1501.3 \\
\hline $\begin{array}{l}\text { Specific consumption of fuel } \\
\text { equivalent }\end{array}$ & $\mathrm{kg} / \mathrm{Gkal}$ & 161.2 & 161.2 & 161.2 & 161.2 \\
\hline $\begin{array}{l}\text { Specific consumption of electrical } \\
\text { energy }\end{array}$ & $\mathrm{W}, \mathrm{Cl}$ & 25.3 & 12.2 & 13.9 & 2.5 \\
\hline
\end{tabular}

When using the extended temperature chart (ETC) without VFD in the area of quality control of heat supply with low water consumption, pressure losses in the RN regulator increase significantly due to the increase in the pressure of network pumps and decrease in pressure losses in the network, however, the energy losses during throttling in the RN regulator decrease. Due to the low flow rate and higher temperature and pressure of forward network water, energy losses at the bypass regulator RB decrease, and energy losses at the regulators of recirculation and temperatures increase. In the field of quantitative control, energy losses approach the losses for the basic mode. 


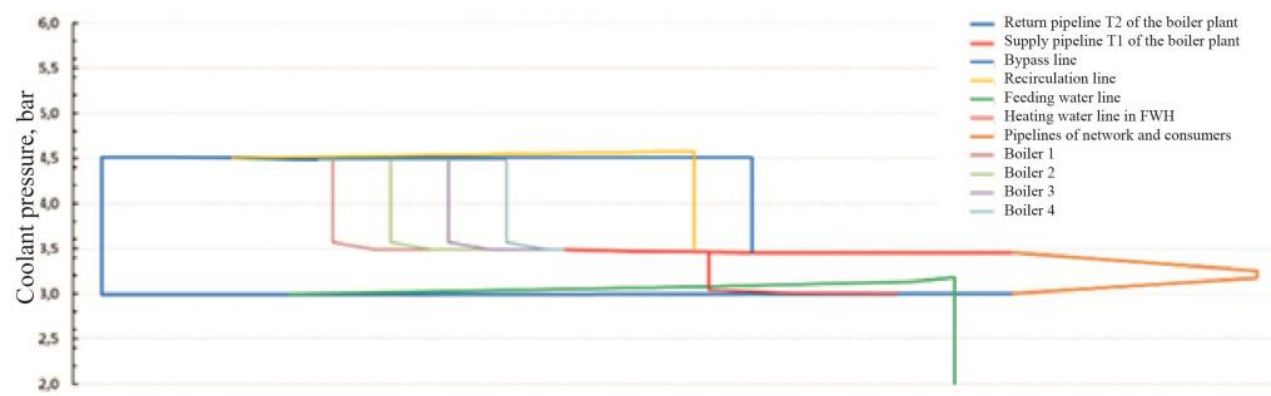

Fig. 5. Regulation using the extended chart using VFD.

The extended temperature chart together with the use of VFD (ETC + VFD) is the most effecient, as it allows one to eliminate pressure and energy losses on the RN, RTr and RP regulators and significantly reduce energy losses on the RT temperature regulator, which is explained by a decrease in pressure losses in the network.

\section{Conclusions}

The conducted research study of the energy efficiency of heating boiler plants using VFD and with various methods of controlling of heat supply showed the following:

1. Modes with the use of VFD at pumps are characterized by a greater reduction in electricity consumption of the boiler plant, which is provided mainly by reducing the cost of driving network pumps. Reducing energy consumption in a normal temperature chart is about $50 \%$.

2. The use of an extended temperature chart, even without using VFD, also reduces the power consumption of the boiler house for about 2 times due to reducing water consumption and energy losses in pipelines, boilers and consumers. In this case, losses of thermal energy in the network increase slightly.

3. The most energy-efficient is the regulation of the extended temperature chart using VFD on the network pumps, as well as on the recirculation and feeding pumps, which reduces the electricity consumption of the boiler equipment by 10 times.

\section{References}

1. Analytical Center of the Government of Russian Federation, Fuel and Energy Complex of Russia / Statistical Collection (FS Rosstat, Moscow, 2017)

2. I.S. Striha, News of heat supply 7, 30-35 (2008)

3. I. V. Kuznik, Industrial power engineering, 3, 2-3 (2009)

4. V.M. Lebedev, S.V. Prikhodko, V.K.Gaak, A.P. Starikov, T.A.Skachko, Industrial power engineering 6, 6-10 (2018)

5. P.V. Rotov, V.S. Sharapov, Electric power stations 9, 16-20 (2011)

6. V.K. Il'in, Electrical Engineering, 7, 16-17 (1995)

7. Yu.S. Vasil'ev, Heat and power engineering, 3, 2-4 (1993)

8. V.S. Petrushin, A.A. Tankov, Electric Machines and Electrical Equipments: Resp. mezhvid. nauh.-tech. Sat 55, 71-75 (2000)

9. O. Muravleva, 8th Korea-Russia International Symposium On Science And Technology, KORUS 1, 264-267 (2004) 
10. E. Ozdemir, Applied Thermal Engineering 7, 981-993 (2004)

11. E.Garibotti, Desalination 1-3, 496-501 (2008)

12. N.F. Il'inskij, Electricity 2, 2-7 (2003)

13. I. Akhmetova, N. Chichirova, O. Derevianko, International Journal of Civil Engineering and Technology 8(12), 694-702 (2017)

14. A.P. Paramonov, M.R. Kadyrov, A.A. Trinchenko, Procedia Engineering 206, 546-551 (2017)

15. J. Saari, E. Sermyagina, J. Kaikko, E. Vakkilainen, V. Sergeev, Energy 113, 574-585 (2016)

16. Resolution of the Government of the Russian Federation of May 6, 2011 N 354 (ed. September 15, 2018) "On the provision of utilities to owners and users of premises in apartment buildings and residential houses".

17. A.A. Pyatin, V.V. Rubleva, ECO-TEK 3, 44-52 (2017)

18. A.A. Pyatin, V.V. Rubleva, ECO-TEK 2, 24-30 (2017)

19. E. Uyanchinov, I. Razov, 5th international youth forum on smart grids, 10-22 (2017)

20. V.V. Gordeev, Yu.A. Ershov, I.A. Sotnikov, A.U. Lipets, I.D. Lisejkin, Heavy engineering 9, 7-13 (1996)

21. A.P. Maltsev, A.A. Zlobin, I.Yu. Medvedeva, G.A.Romanov, Energy security and energy saving 3, 28-33 (2014)

22. D.S. Rakitsky, S.L. Nagorny, P.G. Bykova, V.N. Erchev, M.K. Ageev, Water supply and sanitary engineering 8, 65-70 (2016)

23. L.K. Burulko, L.A. Payuk, Bulletin of Tomsk Polytechnic University 2, 200-203 (2006) 